\title{
The 'Gamgee' turnover flap for lower limb dressing
}

\author{
Shaheel Chummun • Timothy S. Burge
}

Received: 28 November 2010 / Accepted: 28 April 2011 /Published online: 13 May 2011

(C) Springer-Verlag 2011

Sir,

The circumferential application of Gamgee (Gauze tissue BP) dressings over large areas of burns and wounds on the torso and proximal limbs is well-established, providing a dressing that is quick, neat and secure [1]. However, the application of Gamgee to the lower limb can sometimes be awkward. The thigh often has a bigger circumference than the leg, resulting in an excess of Gamgee over the leg and a corresponding deficiency over the thigh area (Fig. 1).

An elegant method of efficiently using all the available Gamgee is to design a turnover flap from the excess Gamgee over the leg area to cover the deficient area over the thigh. The flap is designed as shown (Fig. 2), cut up to the apex at the knee and 'turned over' into the deficient area (Fig. 3). The resulting flap and limb dressing can then be secured with staples, Surgifix ${ }^{\mathrm{TM}}$ netting or crepe

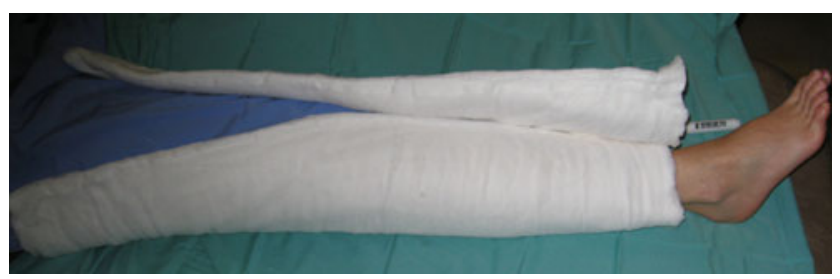

Fig. 1 Deficiency and excess of Gamgee over thigh and leg respectively, as a result of unequal circumference

\footnotetext{
S. Chummun $(\bowtie) \cdot$ T. S. Burge

Department of Plastic Surgery, Frenchay Hospital,

Bristol BS16 1LE, UK

e-mail: shaheelchummun@hotmail.com

T. S. Burge

e-mail: Timothy.Burge@nbt.nhs.uk
}

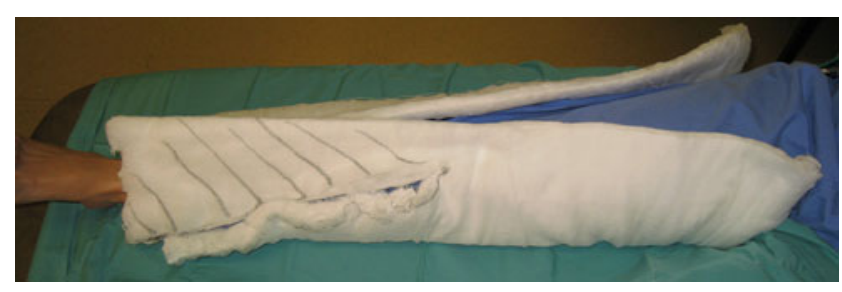

Fig. 2 The excess Gamgee (marked) is designed as the turnover flap

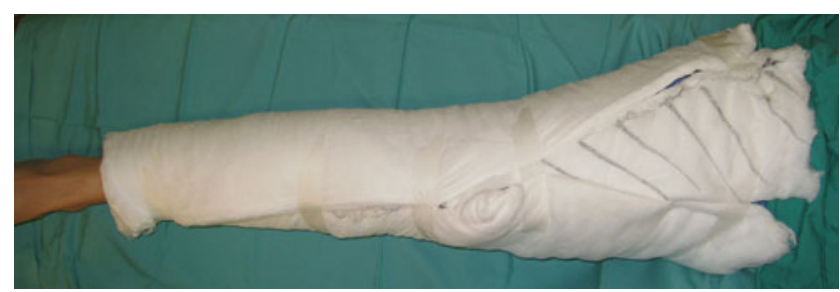

Fig. 3 The flap is turned and secured

bandage. We find this method to be an economical, fast and efficient way of dressing the whole leg.

\section{Reference}

1. Sylaidis P (1996) Staples and Gamgee for securing large-area burns dressings. Burns 22(6):488-489 